\title{
Attention matters: pitch vs. pattern processing in adolescence
}

\section{Elyse S. Sussman*}

Departments of Neuroscience and Otorhinolaryngology-HNS, Albert Einstein College of Medicine, Bronx, NY, USA

Edited by:

Nicole Wetzel, University of Leipzig, Germany

\section{Reviewed by:}

Marie Gomot, Institut National de la Santé et de la Recherche Médicale, France

Anna Shestakova, St. Petersburg State University, Russia

*Correspondence:

Elyse S. Sussman, Departments of Neuroscience and

Otorhinolaryngology-HNS, Albert

Einstein College of Medicine, 1300

Morris Park Avenue, Bronx, NY

10461, USA

e-mail: elyse.sussman@

einstein.yu.edu
From the moment we wake up, we are flooded with more sensory inputs than we can possibly process. Selective attention mechanisms serve to limit the sensory onslaught, while facilitating the ability to perform everyday tasks. However, not much is known about the typical development of selective attention mechanisms during childhood even though impairments of attention are commonly noted in neurodevelopmental disorders. The current study focuses on a transitional time in child development, adolescence, to determine in what way specific auditory tasks have a modulatory effect on underlying brain activity to facilitate behavioral goals. Neural mechanisms of selective attention were tested through auditory pitch and pattern perception, using a measure of event-related brain potentials (ERPs) called the mismatch negativity (MMN). Sounds with a regular five-tone pattern were presented in three conditions. The conditions differed only in how participants were instructed to listen to the sounds. Focus was either on the pitch of the sounds, the pattern of the sounds, or on a close-captioned movie. Even though the sound input was identical in all conditions, task-specific modifications were manifest in the MMN evoked by the deviant sounds embedded in the test sequences. The results demonstrate that in adolescence, as in adults, selective attention alters neural activity specific to performance goals, thus indicating specific neural adaptation modulated by behavior.

\section{INTRODUCTION}

"My experience is what I agree to attend to." (James, 1890, p. 402).

More sensory information reaches us that we can possibly deal with. One of the goals of attention is to limit the amount of information we perceive. When we choose to attend to certain parts of the sensory input it changes our experience of the environment. If I now ask you to direct your attention to your shoes, you can feel the pressure of them against your feet. Though, you probably didn't notice your shoes before I asked you to attend to them even though the sensory information was always available to you. Active selection initiates an interaction between the input (bottom-up processes) and task goals (top-down influences) (Treue, 2001; Beck and Kastner, 2009; Shapiro and Miller, 2011; Miller and Buschman, 2012), modulating the flow of information. This effectively alters our experience of the environment by putting into focus what we choose (or select) to attend to. Attention is adaptive.

It is well known that selecting among inputs can bias underlying neural activity associated with it (Hubel et al., 1959; Desimone and Duncan, 1995; Shomstein and Yantis, 2004). In the biasedcompetition model of visual selective attention (Desimone and Duncan, 1995), for example, when there are multiple objects in a visual scene, the attended object "wins" the competition for neural representation in favor of the unattended objects. Attention mediates the neural responses, enhancing the activity of the selected object. The indication of such results is that attention acts to facilitate behavioral goals.
The current study took a slightly different focus on selective listening, in which selection was initiated by altering task performance with the same set of sounds. There was one stream of sounds that was fully attended to perform different tasks. The "object" was determined by the task requirements that put different attributes of the same sequence into focus, not by competing bottom-up inputs that could be ignored. Thus, competition was derived fully by the task demand and not by ignoring different parts of the input.

Adolescence is a time of considerable growth in both cognitive and brain functions (Crone, 2009). The ability to selectively attend to the environment has been shown to improve during development (Stuss, 1992). Changes in executive function during this time indicate an increased ability to switch between tasks (Crone et al., 2006), to monitor actions (Ladouceur et al., 2010), and to hold items in memory (Crone et al., 2006; Bunge and Wright, 2007). Concurrently, the brain is undergoing continued developmental changes (Gogtay et al., 2004; Blakemore and Choudhury, 2006; Casey et al., 2008), such as a decrease in gray matter consequential to an increase in synaptic pruning (Sowell et al., 2001; Gogtay et al., 2004). Consistent with continued brain maturation through adolescence, the cortically generated obligatory event-related brain potentials (ERPs) that are measured at the scalp have not yet reached the maturity level of adulthood (Ponton et al., 2000; Gilley et al., 2005; Wunderlich and Cone-Wesson, 2006; Sussman et al., 2008). Thus, this developmental time period is a unique age group for investigation, with little known about the link between brain responses and higher level cognitive skills. 
The goal of the current study, in adolescents, was to test taskspecific modulation of neural activity resulting from selectively attending to either the pitch or the pattern of a single stream of sounds to determine how selective attention modulates neural activity associated with task goals. That is, the listener is not selecting a subset of the whole information, but rather refocusing attention to different aspects of the sounds by combining or separating elements of a single sound stream to perform a task.

To test this, we presented a patterned sequence of sounds and instructed participants to focus on the pitches of the sounds (Attend-Pitch condition), the pattern of the sounds (AttendPattern condition), or away from the sounds (Attend-Video condition). The tone pattern in the sequence was determined by two tones occurring in a regularly repeating five-tone pattern (AAAABAAAAB ..., where "A" represents a tone of one frequency and $B$ represents a tone of a slightly higher frequency, Figure 1). A third tone (slightly lower in frequency) was presented randomly, and rarely, in the sequence. This tone served as the target so that participants would never be pressing the response key to the $\mathrm{B}$ tones that provided the dependent measure. Listening to the pitches required focus on the individual sounds to compare among them, whereas listening to the pattern of sounds involved temporally connecting them to perceive the repeating sequence.

We measured components of the ERPs associated with deviance and target detection. In particular, the mismatch negativity (MMN) component was used to index deviance detection. MMN is particularly useful for addressing the question because (1) MMN provides an index of deviance detection regardless of the direction of attention (Näätänen, 1992; Sussman et al., 2003b; Winkler et al., 2005). Therefore, it could be elicited in all conditions of attention; and (2) MMN is highly context dependent (Sussman and Steinschneider, 2006; Rahne et al., 2007; Sussman, 2007; Rahne and Sussman, 2009), and thus can index how sounds are organized in memory. MMN elicitation is based on tones that are detected as deviant in comparison with tones detected as standard (Näätänen, 1992; Näätänen et al., 2001; Sussman, 2007). Based on our previous studies in adults, we expected that selectively listening to the pitches of the sounds vs. the patterns of the sounds would modulate the neurophysiological response to the $\mathrm{B}$ tones in accordance with the task being performed (Sussman et al., 1998, 2002; Sussman and Gumenyuk, 2005).

We predicted that if the B tone was always detected as an infrequently occurring tone of a different frequency than the A tone (focus on pitch), then MMN would be elicited by the B tone in all conditions. In contrast, if the five-tone repeating pattern of the sequence was detected in all conditions (focus on pattern), then no MMN would be elicited by the B tone because it would be held in memory as part of the standard repeating pattern, and not as a deviant. Thus, task modulation of the neural activity to support performance goals would be observed by MMN evoked by B tones only when the pitches of the tones were used to perform the task, but not when the pattern was relevant for the task.

Attend Video

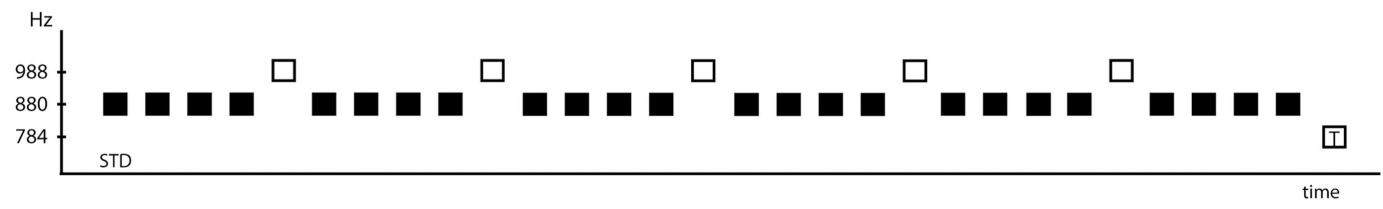

Attend Pitch

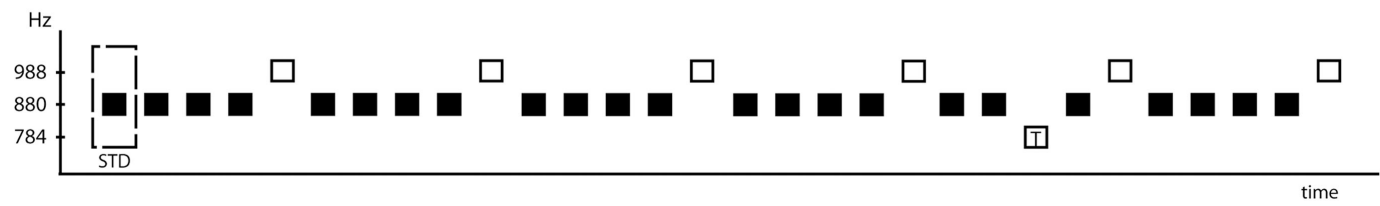

Attend Pattern

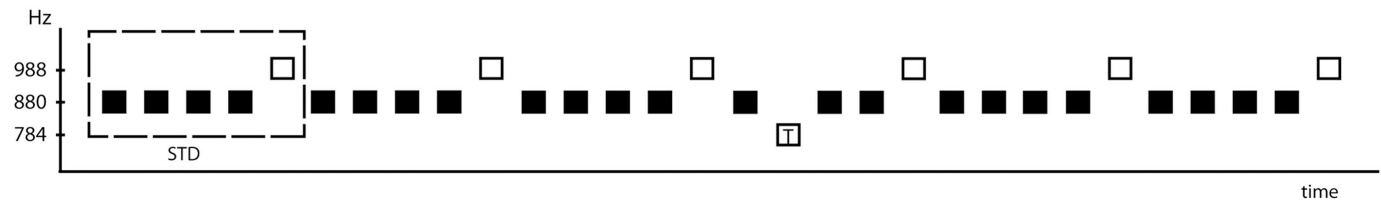

FIGURE 1 | Schematic of the stimulus paradigm. The frequency (in $\mathrm{Hz}$ ) of the tones is indicated on the ordinate and time is represented on the abscissa. The $880 \mathrm{~Hz}$ tones, represented by filled black squares, occurred $80 \%$, and the $988 \mathrm{~Hz}$ tones, represented by the open squares, occurred $18 \%$ The sound sequence containing the five-tone repeating pattern was presented in all three conditions: Attend-Video (top row), Attend-Pitch (middle row), and Attend-Pattern (bottom row). Target tones are represented by the open square with a " $T$ " inside. The position of the target shown in each condition denotes that the target occurred randomly $(2 \%)$, whereas the other tones were presented in a fixed order. The dashed square outlines the smallest tonal element needed to perform the task, thus denoting the standard used in the MMN deviance detection process. 


\section{MATERIALS AND METHODS PARTICIPANTS}

Ten adolescents (six males), ranging in age from 13 to 17 years $(M=15, \mathrm{SD}=1)$ participated in the study. All procedures were approved by the Internal Review Board of the Albert Einstein College of Medicine. Parents were reimbursed for their travel expenses and adolescents were given a gift certificate for their participation. After the experimental protocol was explained to them, parents gave informed consent and children gave written assent. All of the children were in their age-appropriate grade in school, passed a hearing screening test ( $20 \mathrm{~dB}$ HL or better from 500 to $4000 \mathrm{~Hz}$ ), and had no reported history of neurological disorders.

\section{STIMULI}

Three pure tone stimuli, $50 \mathrm{~ms}$ duration $(5 \mathrm{~ms}$ rise/fall time, calibrated to $79 \mathrm{~dB}$ peak-to-peak equivalent using a Brüel and Kjaer 2209 sound level meter), were presented with a $575 \mathrm{~ms}$ onset-toonset pace binaurally through insert earphones. The three stimuli differed only in tone frequency $(784,880$, and $988 \mathrm{~Hz})$. Two of the tones were presented in a continuously repeating five-tone pattern (AAAABAAAAB ..., where " $\mathrm{A}$ " denotes the $880 \mathrm{~Hz}$ tone and " $\mathrm{B}$ " denotes $988 \mathrm{~Hz})$. Thus, the $\mathrm{B}$ tone was presented as every fifth tone in the sequence $(p=0.20)$. The $784 \mathrm{~Hz}$ tone randomly replaced the A tones $(p=0.02)$, and was the target tone when a task was performed with the sounds (Figure 1).

\section{PROCEDURES}

The patterned tone sequences were presented in three conditions of attention: Attend-Pitch, Attend-Pattern, and Attend-Video. In the Attend-Pitch condition, participants were instructed to listen to the three different pitches of the tones and press the response key when they heard the rarely occurring, lowest-pitched tone. In the Attend-Pattern condition, participants were instructed that there was a five-tone repeating pattern of tones in the sequence and to press the response key when they detected a different pattern that occurred rarely. Consequently, in both task conditions, the target tone was the same rarely occurring lower-pitched tone and only the instruction of when to press the response key differed (i.e., for a pitch change or a pattern change). In the Attend-Video condition, participants were told that they would hear sounds in their ears, to ignore the sounds and watch the captioned video of their choosing. Thus, the patterned sequences were played in all three conditions and only the instructions of how to attend to the stimuli differed (attend to the pitch, to the pattern, or ignore the sounds).

Participants sat in a comfortable chair in an electrically shielded and sound-attenuated booth (IAC, Bronx, NY, USA). Five blocks of 300 stimuli were presented for each of the attend conditions ( $\sim 3$ min per block) and three blocks of 500 stimuli $(\sim 5$ min per block) for the ignore condition. Attend condition blocks were shorter than the Ignore condition blocks to reduce sustained attention effects or fatigue that may occur during longer focused task demands. However, the overall presentation amount was the same in all conditions. About $1155 \mathrm{~A}$ tones, $300 \mathrm{~B}$ tones, and 45 target tones were obtained in each condition. Total session time was 1.5$2 \mathrm{~h}$, which included time for electrode placement and breaks. Short breaks (1-3 $\mathrm{min}$ ) were provided in which participants remained seated but took a moment to shift position. One longer break (10-15 $\mathrm{min}$ ) was provided at roughly the mid-point, in which participants were disconnected from the recording system and given time to walk around and have a snack break.

\section{ELECTRODE PLACEMENT AND ELECTROENCEPHALOGRAM RECORDING}

Electroencephalogram recordings were obtained using a 32channel electrode cap that incorporates a subset of the International 10-20 system (Jasper, 1958). Additionally, electrodes were placed over the left and right mastoids (LM and RM, respectively). The tip of the nose was used as the reference electrode during recordings. F7 and F8 electrode sites were used in a bipolar configuration to monitor the horizontal electro-oculogram (HEOG). FP1 and an electrode placed below the left eye were used in a bipolar configuration to monitor the vertical electro-oculogram (VEOG). All impedances were maintained below $5 \mathrm{k} \Omega$. The EEG and EOG were digitized (Neuroscan SynAmps amplifier, Compumedics Corp., El Paso, TX, USA) at a sampling rate of $500 \mathrm{~Hz}$ (0.05-100 Hz bandpass). EEG was then filtered offline (Butterworth, zero phase shift) with a lowpass designation of $30 \mathrm{~Hz}$. Artifact rejection was set to exclude activity exceeding $100 \mu \mathrm{V}$ after EEG epochs were baseline corrected. Epochs were $600 \mathrm{~ms}$ in duration, starting $100 \mathrm{~ms}$ pre-stimulus onset and ending $500 \mathrm{~ms}$ post-stimulus onset.

\section{DATA REDUCTION AND ANALYSIS}

ERPs evoked by each stimulus type was separately averaged together. Responses evoked by the A tone immediately following the $\mathrm{B}$ tone were excluded from analysis. Approximately $10 \%$ of the overall epochs were rejected due to artifact. The MMN component was statistically measured using a $40 \mathrm{~ms}$ window centered on the peak obtained at the mastoid electrodes in the grand-mean difference waveforms. The inversion at the mastoid that is typically observed for the MMN component was used to obtain a peak measurement because of overlap at frontal electrode sites (e.g., $\mathrm{Fz}$ ) with the $\mathrm{N} 2$ component in the sound task conditions. Fz was used in the Attend-Video condition. The peak of $152 \mathrm{~ms}$ was used for the Attend-Pitch and Attend-Pattern conditions for all stimulus types. In the Attend-Video conditions, the peak was $174 \mathrm{~ms}$ for all stimulus types. The $\mathrm{N} 2$ component was measured using a $40 \mathrm{~ms}$ window centered on the peak in the grand-mean difference waveform peak at the $\mathrm{Cz}$ electrode (greatest $\mathrm{S} / \mathrm{N}$ ratio), with a peak latency of $218 \mathrm{~ms}$ in the Attend-Pattern condition, and $202 \mathrm{~ms}$ in the Attend-Pitch condition. The P3b component was measured using a $50 \mathrm{~ms}$ window centered on the peak of the grand-mean difference waveform at the $\mathrm{Pz}$ electrode (greatest $\mathrm{S} / \mathrm{N}$ ratio), with a peak latency of $364 \mathrm{~ms}$ in the Attend-Pattern condition, and $354 \mathrm{~ms}$ in the Attend-Pitch condition. No attention-related components were elicited in the Attend-Video condition because the sounds were ignored.

To statistically verify the presence of the MMN, N2, and P3b components, one-sample $t$-tests were conducted to determine whether the mean amplitude at the electrode of greatest signal-tonoise ratio for each component ( Fz for MMN, Fz for target-N2, and $\mathrm{Pz}$ for P3b) was significantly greater than zero. To compare amplitudes of the components across conditions, repeated-measures analysis of variance (ANOVA) was calculated and Huynh-Feldt 
corrections were reported as appropriate. Fisher's least significant difference (LSD) test was performed for all post hoc calculations. Hits, misses, false alarms, and correct rejections were calculated to determine accuracy of behavioral responses to the target tones. Button press responses were considered correct if they occurred between 100 and $900 \mathrm{~ms}$ from target stimulus onset. Student's $t$-test for dependent measures was used to determine whether the hit rate (HR), false alarm rate (FAR), and reaction time (RT) differed between target types (Attend-Pitch vs. Attend-Pattern).

\section{RESULTS}

\section{BEHAVIORAL RESULTS}

Hit rate to targets was high in both the Attend-Pattern $(M=0.93$, $\mathrm{SD}=0.07)$ and Attend-Pitch $(M=0.95, \mathrm{SD}=0.04)$ conditions, with no significant difference between them $\left(t_{9}=1.03, p=0.33\right)$. FAR was low in both conditions $(M=0.001, \mathrm{SD}<0.01)$ and also did not significantly differ by task $\left(t_{9}<1, p=0.80\right)$. RT to targets in the Attend-Pattern $(M=463, \mathrm{SD}=84)$ and Attend-Pitch $(M=463, \mathrm{SD}=86)$ conditions also did not significantly differ by task $\left(t_{9}<1, p=0.96\right)$. Overall, there were no task effects on HR, RT, or FAR.

\section{ERP RESULTS}

Figure 2 displays the ERPs elicited by the standard stimuli, overlaying the responses from each condition of attention. In adolescence, the P1 (peak 68 ms), N1 (peak $90 \mathrm{~ms}$ ), P2 (peak $144 \mathrm{~ms}$ ), and the obligatory-N2 (peak $\sim 276 \mathrm{~ms}$ ) were observed in the standard waveforms. Observed peak latencies and amplitudes of the obligatory components are consistent with their age (Ponton et al., 2000; Sussman et al., 2008).

Figure 3 displays the ERPs evoked by the A and B tones overlain for the Attend-Pattern, Attend-Pitch, and Attend-Video conditions at the midline $(\mathrm{Fz}, \mathrm{Cz}$, and $\mathrm{Pz}$ ) electrodes. Table 1 provides the mean amplitudes of the difference (response to B-minus-response to A) waveforms for the ERP components, and statistical presence of MMN, target-N2, and P3b components.

Figure 4 displays the difference waveforms (ERP response to the $\mathrm{B}$ tone-minus-ERP response to the A tone) and voltage maps. MMNs were elicited by the target tones in all conditions (Table 1). MMNs were elicited by the B tones (the final tone of the standard repeating pattern) in the Attend-Pitch and in the Attend-Video conditions, but not in the Attend-Pattern condition (Table 1). The amplitudes of the MMNs elicited by the target tones were larger than the MMN elicited by the B tones $\left(F_{1,9}=32.13, p<0.001\right)$.

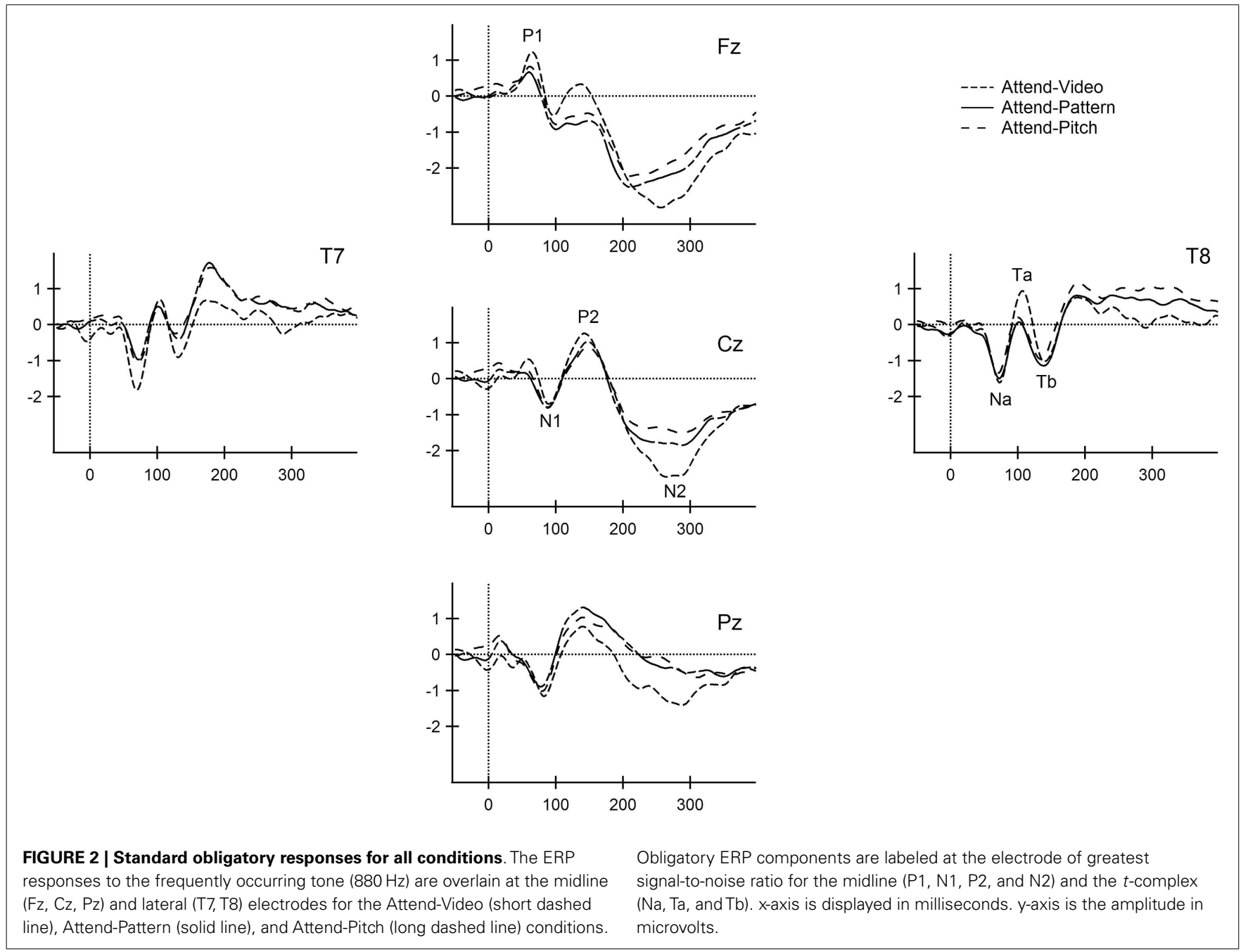




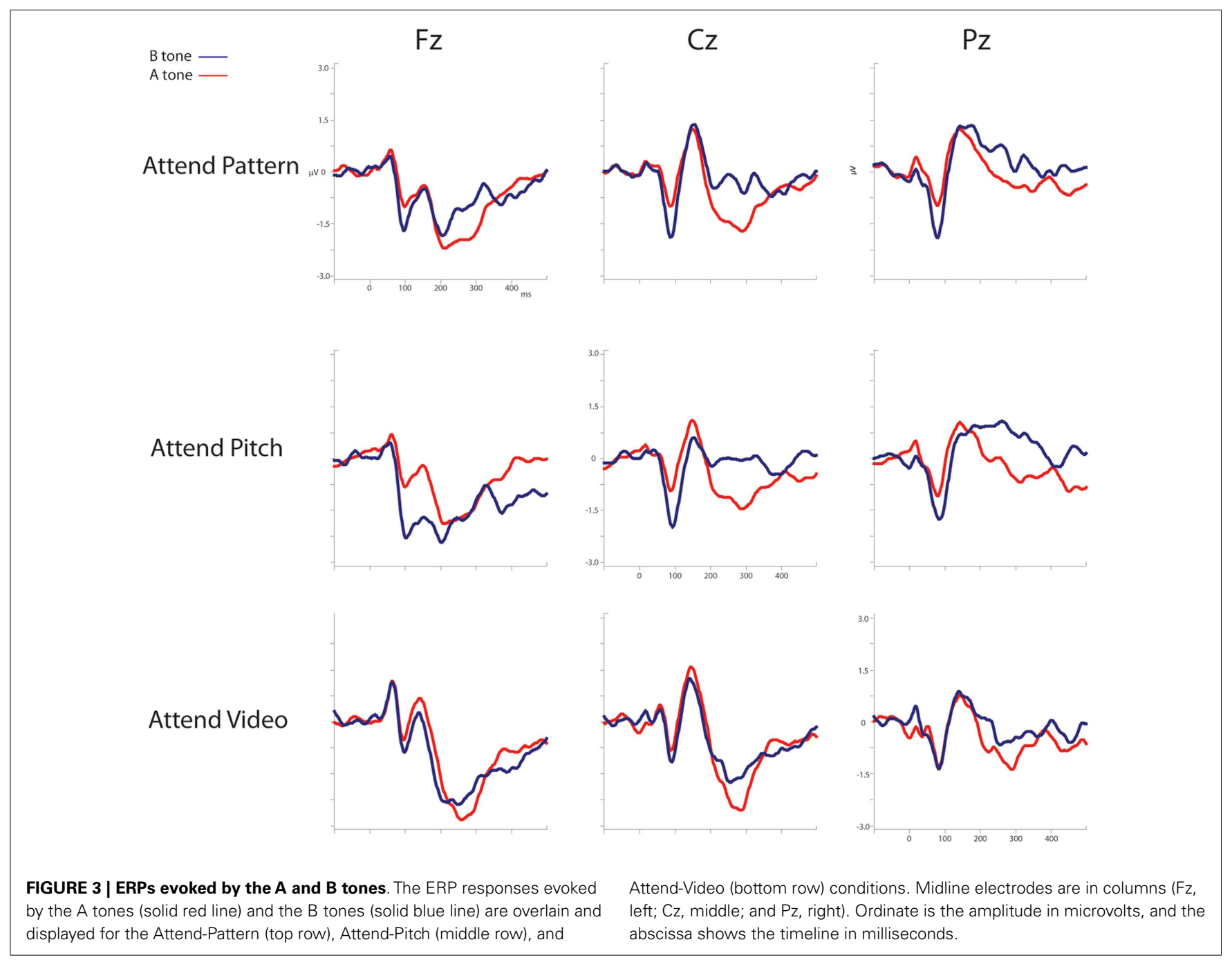

To determine whether there was an effect of task on MMN, a twoway repeated-measures ANOVA was conducted on the difference waveforms with factors of Attention (Pattern/Pitch/Video) and Electrode (Fz, F3, F4). There was no effect of attention on MMN amplitude for the target tones $\left(F_{2,18}<1, p=0.42\right)$, nor was there a topographic difference (no main effect of electrode: $F_{2,18}=1$, $i=0.38$ ), and no interaction. In contrast, there was a main effect of attention on B tones $\left(F_{2,18}=4.96, \varepsilon=0.86, p=0.019\right)$. Post hoc calculation showed that MMN amplitude in the Attend-Pitch condition $(-1.47 \mu \mathrm{V})$ was larger than that in the Attend-Video condition $(-0.80 \mu \mathrm{V})$, and both MMNs were larger than the amplitude evoked in the Attend-Pattern condition $(-0.26 \mu \mathrm{V})$, where there was no significant MMN.

Target-N2 and P3b components were elicited only to target stimuli (Table 1; Figure 4) when either the pattern or the pitch of the sounds was attended (Attend-Pattern and Attend-Pitch conditions), but not when the sounds were ignored (Attend-Video condition), as would be expected. For the target-N2, two-way repeated-measures ANOVA were conducted on the difference waveforms with factors of attention (pattern vs. pitch) and electrode $(\mathrm{Fz}, \mathrm{F} 3, \mathrm{~F} 4, \mathrm{Cz}, \mathrm{C} 3, \mathrm{C} 4)$ to assess task effects. There was no difference in amplitude according to task (no main effect of attention, $F_{1,9}<1, p=0.92$ ), and no main effect of electrode after correction $\left(F_{5,45}=2.83, \varepsilon=0.52, p=0.067\right)$, indicating that the target-N2 had a fronto-central distribution in adolescence. For the target-P3b, a two-way repeated-measures ANOVA was conducted on the difference waveforms with factors of attention (pattern vs. pitch) and electrode (Pz, P3, P4) to assess task effects. Similarly, task had no effect on the target-P3b (no main effect of attention, $\left.F_{1,9}<1, p=0.70\right)$. However, there was a main effect of electrode $\left(F_{2,18}=7.15, \varepsilon=0.99, p=0.005\right)$. Post hoc calculations showed that the amplitude was largest at the Pz electrode, which is a distribution that is similar to adults.

\section{DISCUSSION}

The goal of the study was to assess, in adolescence, task-specific modulation of neural activity resulting from selectively attending to either the pitch or the pattern of sounds in a sequence. In all conditions, the sound sequences were presented in a fixed temporal order (AAAABAAAAB ...), and only the task instructions differed. The main finding was that the task performance modulated the brain's response to the sound. This was demonstrated by the 
Table 1 | ERP component mean amplitudes.

\begin{tabular}{|c|c|c|c|c|}
\hline Attend/stimulus & Mean & SD & $t$-value & $\begin{array}{l}{ }^{*} \leq 0.05 ;{ }^{*} \leq 0.01 \\
\text { ns, not sig. }\end{array}$ \\
\hline \multicolumn{5}{|l|}{ MMN (Fz) } \\
\hline Pattern/Target & -4.85 & 3.66 & -4.19 & $* *$ \\
\hline Pattern/B & -0.23 & 1.45 & -0.51 & ns \\
\hline Pitch/Target & -4.25 & 1.93 & -6.96 & $* *$ \\
\hline Pitch/B & -1.43 & 1.07 & -4.24 & $* *$ \\
\hline Video/Target & -3.51 & 4.30 & -2.58 & $*$ \\
\hline Video/B & -0.87 & 1.32 & -2.08 & * \\
\hline \multicolumn{5}{|l|}{ N2 (Fz) } \\
\hline Pattern/Target & -7.63 & 5.12 & -4.71 & ** \\
\hline Pattern/B & 0.53 & 1.44 & 1.16 & $\mathrm{~ns}$ \\
\hline Pitch/Target & -7.15 & 4.42 & -5.11 & $* *$ \\
\hline Pitch/B & -0.47 & 1.31 & -1.13 & ns \\
\hline \multicolumn{5}{|l|}{ P3b (Pz) } \\
\hline Pattern/Target & 16.02 & 10.46 & 4.84 & ** \\
\hline Pattern/B & 0.44 & 1.00 & 1.38 & ns \\
\hline Pitch/Target & 14.98 & 9.90 & 4.79 & $* *$ \\
\hline Pitch/B & 0.71 & 1.31 & 1.71 & ns \\
\hline
\end{tabular}

MMN response to the B tones under the different task conditions. When the pitches of the sounds were relevant to performing the task, MMN was elicited by the infrequently occurring B tones. In contrast, when the pattern of sounds was relevant to perform the task, no MMN was elicited by the B tones, as they were an integral part of the repeating standard pattern. That is, the same regularly occurring $\mathrm{B}$ tones evoked different brain responses depending on their relevance in performing the task. These results thus demonstrate that selective attention alters neural activity, adapting the neural response to the pertinent elements of the input required for performing a task: in this case, adapting to a five-tone standard in one condition and to single tone standard in the other.

The target $784 \mathrm{~Hz}$ tone was a deviant in both conditions, even though in the Attend-Pattern condition the target tone was a "pattern deviant" and in the Attend-Pitch condition it was a "pitch deviant." MMN, target-N2, and P3b components were elicited by the targets. In the current study, in the adolescents, the target-detection $\mathrm{N} 2$ component had a more fronto-central scalp distribution than the more centro-parietal distribution generally found in adults. This could be due to overlap of multiple $\mathrm{N} 2$ components in adolescents, if, for example, anterior cingulate cortex were more involved in performing the task. This would be consistent with continued changes occurring in prefrontal cortex through adolescence (Blakemore and Choudhury, 2006). The target-P3b component, on the other hand, had a similar topography to that found in adults, with its maximal peak at the Pz electrode (Friedman and Simpson, 1994; Fabiani et al., 1998).

In contrast, the B tones had a functionally different role in the two conditions depending on whether the listener was detecting separate pitches, or the sequential five-tone pattern. The B tones were used to perform the task but were not target tones, and required no button presses in any of the three conditions. The $\mathrm{B}$ tones were deviants in the Attend-Pitch condition, on the basis of probability of occurrence (Sussman et al., 2003a), and MMN was elicited by them. The absence of MMN to the B tones in the Attend-Pattern condition can be explained by their function in the sequence as a part of the repeating standard pattern: they were not deviant. Thus, the way in which the sounds were used to perform the task altered the repeating standard that was maintained in memory, which modulated the change-detection process (Sussman, 2007).

When participants had no task with the sounds (Attend-Video condition), MMNs were elicited by both the $\mathrm{B}$ tones and the target $(784 \mathrm{~Hz})$ tones. This suggests that the regularity of the sequence was not automatically detected, which may be explained solely by the stimulus rate. The $575 \mathrm{~ms}$ onset-to-onset pace may have been too slow for automatic detection of the pattern while attending the video (Sussman and Gumenyuk, 2005; Wang et al., 2009). An alternative explanation, in conjunction with the slow presentation rate, is that MMN elicitation to B tones occurred because the patterning of the sequence was irrelevant to the task (watching a video), whether or not the B tones were detected as occurring regularly. This would suggest that MMN was elicited strictly on the basis of the ratio of tone frequencies within the sound sequence (Sussman et al., 2002; Sussman and Gumenyuk, 2005), with the A tones occurring frequently (standard) and the $\mathrm{B}$ tones and target tones both infrequently (deviants) (Sussman et al., 2003a).

Further, these results are consistent with previous studies using similar paradigms in adult participants (Sussman et al., 1998, 2002; Sussman and Gumenyuk, 2005), indicating that top-down processes in adolescence have similar modulatory effects in facilitating task goals. Even though the obligatory cortical ERPs in adolescents are not yet adult-like, they differ both in morphology and scalp distribution compared to adults (Sussman et al., 2008), task effects evoking the MMN component appear to be similar. This suggests that the MMN component, which is driven by the internal state of the individual, reflects aspects of auditory cognition not strictly bound to cortical maturation, which is consistent with findings of MMN elicitation in infants and toddlers (Shafer et al., 2000; Huotilainen et al., 2003).

Finally, the ability to selectively attend to sounds and ignore irrelevant sounds in the environment has important implications for clinical populations. The paradigm of the current study may be useful for testing various clinical populations. This is because changes in the neurophysiologic responses can be attributed to attentional control and not to differences in the physical characteristics of the stimuli or to the stimulus presentation rate, since the physical auditory input was the same in all conditions. This protocol may thus provide a unique way to assess attention deficits in various neurodevelopmental disorders.

\section{SUMMARY}

The same tone evoked different change-detection responses specific to the task, not the stimulus input. This is consistent with studies demonstrating task-specific effects in the visual system (Beck and Kastner, 2009), and consistent with idea that attention is an "emergent property" of competitive interactions with stimulus-driven processes (Desimone and Duncan, 1995). In the 


\section{A Difference Waveforms}
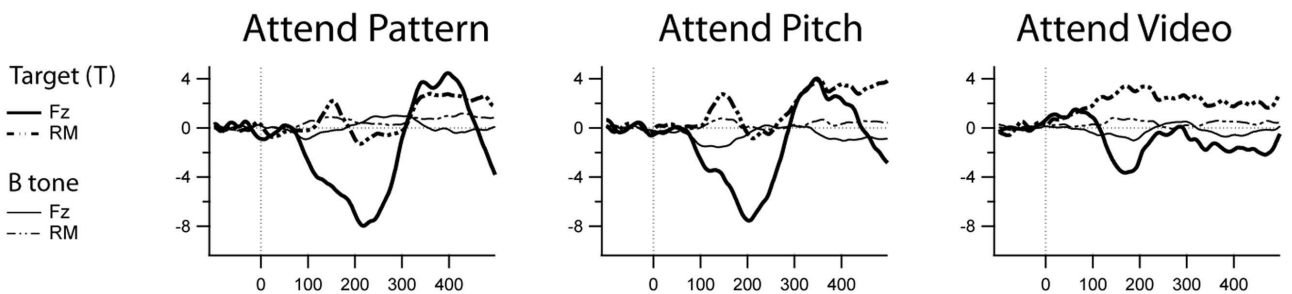

B Scalp Voltage Maps
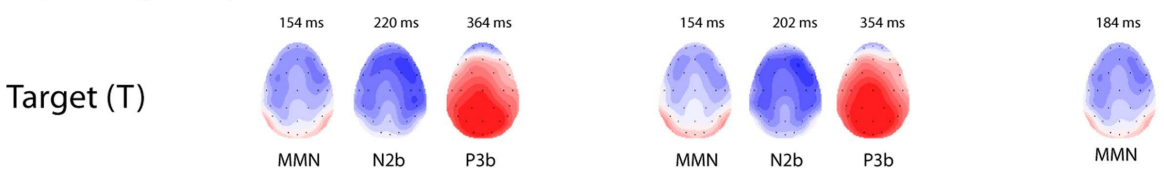

B tone
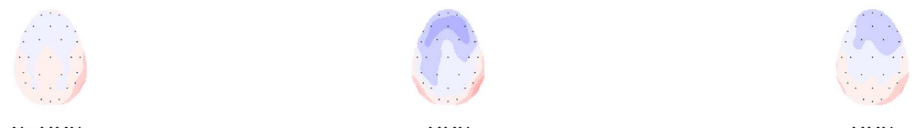

No MMN

MMN

MMN

c Stimulus Sequence

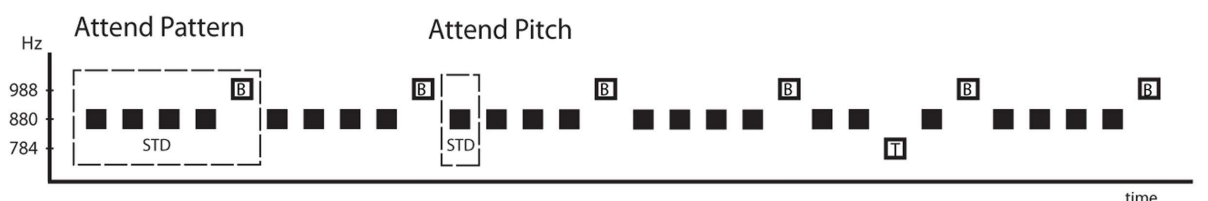

FIGURE 4 | Difference waveforms and scalp voltage maps for all conditions. (A) Difference waveforms (top row) are displayed for the target tones (thick lines) and B tones (thin lines) at Fz (solid line) and the left mastoid (LM, dashed lines) in the Attend-Pattern (left column), Attend-Pitch (middle column), and Attend-Video (right column). (B) Scalp voltage maps (middle row) are displayed at the peak of the ERP components (peak latency above the head shots, and the ERP components labeled below). No MMN was elicited by the B tone in the Attend-Pattern condition. Target-N2 and P3b components were not elicited in the Attend-Video condition, in which the sounds were ignored. (C) Stimulus sequence (bottom row) is displayed as a reminder of the stimulus-eliciting tones. " $T$ " denotes the target tones when sounds were attended and " $B$ " denotes the fifth tone of the pattern.

current study, even though the stimulus-driven input was biased toward the patterned sequence, attention mediated the neural activity to support performance goals. Task-dependent facilitation was demonstrated in that the neural response adapted either to the single tone standard or to the five-tone pattern standard inherent in the sequence. Overall, the results show, in adolescence as in adults, that attention plays an important role in modulating neural activity to facilitate performance,

\section{REFERENCES}

Beck, D. M., and Kastner, S. (2009). Topdown and bottom-up mechanisms in biasing competition in the human brain. Vision Res. 49, 1154-1165. doi:10.1016/j.visres.2008.07.012

Blakemore, S.-J., and Choudhury, S. (2006). Development of the adolescent brain: implications for executive function and social cognition. J. Child. Psychol. Psychiatry 47, 296-312. doi:10.1111/j.14697610.2006.01611.x

Bunge, S. S., and Wright, S. B. (2007). Neurodevelopmental changes in working memory and cognitive control. Curr. Opin. Neurobiol. 17, 243-250. doi:10.1016/j.conb.2007.02.005

Casey, B. J., Jones, R. M., and Hare, T. A. (2008). The adolescent brain. Ann. N. Y. Acad. Sci. 1124, 111-126. doi:10.1196/annals.1440.010

Crone, A. (2009). Executive functions in adolescence: inferences from brain and behavior. Dev. Sci. 12, 825-830. doi:10.1111/j.14677687.2009.00918.x

Crone, E., Bunge, S. A., van der Molen, M. W., and Ridderinkhof,

adjusting the time scale of adaptation dependent upon task goals.

\section{ACKNOWLEDGMENTS}

This research was supported by the NIH (R01 DC004263). I express my gratitude to Jean DeMarco for assistance with subject preparation, and to Aaron Bendich, WeiWei Lee, and Grace Sadia for assistance with data collection and data processing.

K. R. (2006). Switching between tasks and responses: a developmental study. Dev. Sci. 9, 278-287. doi:10.1111/j.14677687.2006.00490.x

Desimone, R., and Duncan, J. (1995). Neural mechanisms of selective visual attention. Annu. Rev. Neurosci. 18, 193-222. doi:10.1146/annurev.ne.18.030195. 001205

Fabiani, M., Friedman, D., and Cheng, J. C. (1998). Individual differences in P3 scalp distribution in older adults, and their relationship to frontal lobe function. Psychophysiology 35, 698-708. doi:10.1111/14698986.3560698

Friedman, D., and Simpson, G. V. (1994). ERP amplitude and scalp distribution to target and novel events: effects of temporal order in young, middle-aged and older adults. Brain Res. Cogn. Brain Res. 2, 49-63. doi:10.1016/09266410(94)90020-5

Gilley, P. M., Sharma, A., Dorman, M., and Martin, K. (2005). Developmental changes in refractoriness of the cortical auditory evoked potential. 
Clin. Neurophysiol. 116, 648-657. doi:10.1016/j.clinph.2004.09.009

Gogtay, N., Giedd, J. N., Lusk, L., Hayashi, K. M., Greenstein, D., Vaituzis, A. C., et al. (2004). Dynamic mapping of human cortical development during childhood through early adulthood. Proc. Natl. Acad. Sci. U.S.A. 101, 8174-8179. doi:10.1073/pnas.0402680101

Hubel, D. H., Henson, C. O., Rupert, A., and Calambos, R. (1959). Attention units in the auditory cortex. Science 129, 1279-1280. doi:10.1126/science.129.3358.1279

Huotilainen, M., Kujala, A., Hotakainen, M., Shestakova, A., Kusherenko, E., Parkonen, L., et al. (2003). Auditory magnetic responses of healthy newborns. Neuroreport 14, 1871-1875. doi:10.1097/00001756200310060-00023

James, W. (1890). Principles of Psychology, Vol. 1. New York: Dover Publications, 402.

Jasper, H. H. (1958). Report of the committee on methods of clinical examination in electroencephalography. Electroencephalogr. Clin. Neurophysiol. 10, 370-371. doi:10.1016/00134694(58)90053-1

Ladouceur, C. D., Conway, A., and Dahl, R. E. (2010). Attentional control moderates relations between negative affect and neural correlates of action monitoring in adolescence. Dev. Neuropsychol. 35, 194-211. doi:10.1080/87565640903526553

Miller, E. K., and Buschman, T. J. (2012). Cortical circuits for the control of attention. Curr. Opin. Neurobiol. 23, $1-7$.

Näätänen, R. (1992). Attention and Brain Function. Hillsdale, NJ: Erlbaum.

Näätänen, R., Tervaniemi, M., Sussman, E., Paavilainen, P., and Winkler, I. (2001). "Primitive intelligence" in auditory cortex. Trends Neurosci. 24, 283-288. doi:10.1016/S01662236(00)01790-2
Ponton, C. W., Eggermont, J. J., Kwong, B., and Don, M. (2000). Maturation of human central auditory system activity: evidence from multichannel evoked potentials. Clin. Neurophysiol. 111, 220-236. doi:10. 1016/S1388-2457(99)00236-9

Rahne, T., Böckmann, M., von Specht, H., and Sussman, E. (2007). Visual cues can modulate integration and segregation of objects in auditory scene analysis. Brain Res. 1144, 127-135. doi:10.1016/j.brainres.2007.01.074

Rahne, T., and Sussman, E. (2009). Neural representations of auditory input accommodate to the context in a dynamically changing acoustic environment. Eur. J. Neurosci. 29, 205-211. doi:10.1111/j.14609568.2008.06561.x

Shafer, V. L., Morr, M. L., Kruezer, J. A., and Kurtzberg, D. (2000). Maturation of mismatch negativity in school-age children. Ear Hear. 21, 242-251. doi:10.1097/00003446200006000-00008

Shapiro, K. L., and Miller, C. E. (2011). The role of biased competition in visual short-term memory. Neuropsychologia 49, 1506-1517. doi:10.1016/j.neuropsychologia.2011. 02.017

Shomstein, S., and Yantis, S. (2004). Control of attention shifts between vision and audition in human cortex. J. Neurosci. 24, 10702-10706. doi:10.1523/JNEUROSCI.293904.2004

Sowell, E. R., Thompson, P. M., Tessner, K. D., and Toga, A. W. (2001). Mapping continued brain growth and gray matter density reduction in dorsal frontal cortex: inverse relationships during postadolescent brain maturation. J. Neurosci. 21, 8819-8829.

Stuss, D. T. (1992). Biological and psychological development of executive functions. Brain $\operatorname{Cogn}$. 20, 8-23. doi:10.1016/0278-2626(92)90059-U
Sussman, E. (2007). A new view on the MMN and attention debate: auditory context effects. Int J. Psychophysiol. 21, 164-175. doi:10.1027/0269-8803.21.34.164

Sussman, E., and Gumenyuk, V. (2005). Organization of sequential sounds in auditory memory. Neuroreport 16, 1519-1523. doi:10.1097/01.wnr.0000177002.35 $193.4 \mathrm{c}$

Sussman, E., Ritter, W., and Vaughan, H. G. Jr. (1998). Predictability of stimulus deviance and the mismatch negativity. Neuroreport 9, 4167-4170. doi:10.1097/00001756199812210-00031

Sussman, E., Sheridan, K., Kreuzer, J., and Winkler, I. (2003a). Representation of the standard: stimulus context effects on the process generating the mismatch negativity component of event-related brain potentials. Psychophysiology 40, 465-471. doi:10.1111/1469-8986.00048

Sussman, E., Winkler, I., and Wang, W. (2003b). MMN and attention: competition for deviance detection. Psychophysiology 40, 430-435. doi:10.1111/1469-8986.00045

Sussman, E., and Steinschneider, M (2006). Context-dependent encoding of sensory input in auditory cortex. Brain Res. 1075, 165-174. doi:10.1016/j.brainres.2005. 12.074

Sussman, E., Steinschneider, M. Gumenyuk, V., Grushko, J., and Lawson, K. (2008). The maturation of human evoked brain potentials to sounds presented at different stimulus rates. Hear. Res. 236, 61-79. doi:10.1016/j.heares.2007.12.001

Sussman, E., Winkler, I., Huoutilainen, M., Ritter, W., and Naatanen, R. (2002). Top-down effects can modify the initially stimulus-driven auditory organization. Brain Res. Cogn. Brain Res. 13, 393-405. doi:10.1016/S0926-6410(01)00 $131-8$
Treue, S. (2001). Neural correlates of attention in primate visual cortex. Trends Neurosci. 24, 295-300. doi:10.1016/S0166-2236(00)01 814-2

Wang, J., Staffaroni, L., Reid, E., Steinschneider, M., and Sussman, E. (2009). Effects of musical training on pattern perception in adolescents. Int. J. Pediatr. Otorhinolaryngol. 73, 751-755. doi:10.1016/j.ijporl.2009.02.003

Winkler, I., Czigler, I., Sussman, E. Horváth, J., and Balázs, L. (2005). Preattentive binding of auditory and visual stimulus features. $J$. Cogn. Neurosci. 17, 320-339. doi:10.1162/0898929053124866

Wunderlich, J. L., and Cone-Wesson, B. K. (2006). Maturation of CAEP in infants and children: a review. Hear. Res. 212, 212-223. doi:10.1016/j.heares.2005.11.008

Conflict of Interest Statement: The authors declare that the research was conducted in the absence of any commercial or financial relationships that could be construed as a potential conflict of interest.

Received: 25 March 2013; paper pending published: 08 May 2013; accepted: 22 May 2013; published online: 10 June 2013.

Citation: Sussman ES (2013) Attention matters: pitch vs. pattern processing in adolescence. Front. Psychol. 4:333. doi: 10.3389/fpsyg.2013.00333

This article was submitted to Frontiers in Developmental Psychology, a specialty of Frontiers in Psychology.

Copyright () 2013 Sussman. This is an open-access article distributed under the terms of the Creative Commons Attribution License, which permits use, distribution and reproduction in other forums, provided the original authors and source are credited and subject to any copyright notices concerning any third-party graphics etc. 